\title{
Efeitos da Insulação Escrotal sobre a Biometria Testicular e Parâmetros Seminais em Carneiros da Raça Santa Inês Criados no Estado do Ceará ${ }^{1}$
}

\author{
Emerson Pinto Moreira², Arlindo de Alencar Araripe Moura ${ }^{3}$, Airton Alencar de Araújo 4
}

\begin{abstract}
RESUMO - Um estudo foi conduzido com a finalidade de avaliar o efeito do estresse térmico sobre parâmetros seminais e biometria testicular em carneiros Santa Inês. Oito animais adultos foram submetidos à insulação escrotal por sete dias. Realizaram-se duas avaliações antes da insulação e, após este período, doze coletas durante 118 dias. A insulação escrotal não causou variações no volume dos ejaculados, mas o pH seminal apresentou valores elevados oito dias após a insulação, retornando à normalidade após 15 dias. Ocorreu redução na concentração espermática oito dias após a insulação e os animais apresentaram azoospermia entre 33 e 50 dias. Depois de 79 dias, a concentração espermática retornou aos padrões observados antes da insulação. A circunferência escrotal $(26,4 \mathrm{~cm})$ reduziu para 22,4 cm oito dias após o término do tratamento e para $21 \mathrm{~cm}$ aos 21 dias, mas retornou a valores próximos à normalidade $(24,9 \mathrm{~cm})$ aos 50 dias. Foi observado decréscimo na motilidade e vigor espermático a partir da retirada da bolsa e o retorno destes parâmetros à normalidade ocorreu somente após 90 dias. Antes da insulação, 1,7\% dos espermatozóides apresentaram-se com defeitos maiores e 9,9\%, com defeitos menores. Na primeira coleta após a insulação, 3,6\% das células apresentaram defeitos maiores e 43,4 \%, defeitos menores; aos oito dias, estes valores foram de 8,4 e 60,4\%, respectivamente. Entre 15 e 60 dias após a insulação, a percentagem de defeitos maiores variou entre 27,3 e 16,8\%, enquanto a de defeitos menores permaneceu em torno de 39\%. Aos 118 dias após a insulação, os defeitos maiores representaram somente $0,7 \%$, mas o número de células com defeitos menores continuou elevado $(24,4 \%)$. Portanto, o estresse térmico causou interrupção temporária do processo de produção espermática e os parâmetros relativos à motilidade e defeitos menores apresentaram maior susceptibilidade.
\end{abstract}

Palavras-chave: carneiros, estresse térmico, sêmen, testículos

\section{Effects of Scrotal Insulation on Testis Size and Semen Criteria in Santa Inês Hairy Sheep Raised in the State of Ceará, Northeast of Brazil}

\begin{abstract}
A study was conducted to determine the effect of heat stress on semen criteria and testis size in Santa Inês hairy rams, in the State of Ceará, Northeast of Brazil. The scrotum of eight adult rams was insulated for seven days. Animals were evaluated twice before insulation and, after insulation, at 12 different periods until 118 days. Scrotal insulation did not affect semen volume, but $\mathrm{pH}$ was increased after eight days, returning to normal values after 15 days. Sperm concentration was reduced eight days after insulation was removed and animals became azzospermic between 33 and 50 days. After 79 days, sperm concentration returned to values similar to those observed before treatment. Scrotal circumference $(26.4 \mathrm{~cm})$ decreased to $22.4 \mathrm{~cm}$ eight days after insulation and to $21 \mathrm{~cm}$ at 21 days, but returned to 24.9 $\mathrm{cm}$ after 50 days. Moreover, sperm motility and vigor were reduced right after insulation was removed and returned to normal profiles only after 90 days. Before treatment, there were $1.7 \%$ of sperm cells with primary defects and $9.9 \%$ with secondary defects. Right after insulation, sperm cells with primary defects increased to $3.6 \%$ and those with secondary defects, to $43.4 \%$, and after eight days, these values increased to 8.4 and $60.4 \%$, respectively. From 15 to 60 days, sperm cells with primary defects varied from 27.3 to $16.8 \%$, while those with secondary defects showed only small variations (39.9 to 39\%). At the end of the experiment (118 days after insulation), primary defects were reduced to $0.7 \%$, but the percentage of cells with secondary defects was still high $(24.4 \%)$. Therefore, heat stress caused temporary interruption of sperm production in the ram and sperm motility and secondary defects seemed to be the most sensitive criteria.
\end{abstract}

Key Words: heat stress, testis, rams, semen

\section{Introdução}

Os testículos dos mamíferos encontram-se alojados no interior da bolsa escrotal e a temperatura testicular mantém-se entre 2 e $6^{\circ} \mathrm{C}$ abaixo da temperatura corporal (KASTELIC et al., 1995; WAITES,
1970). Vários fatores contribuem para a termoregulação escroto-testicular, incluindo a estrutura penduncular do escroto e a vascularização testicular que, por meio do plexo pampiniforme, reduz a temperatura escrotal pela troca de calor entre o sangue circulante na artéria e na veia testicular (COULTER e KASTELIC, 1994;

\footnotetext{
${ }^{1}$ Parte do experimento de dissertação de Mestrado do primeiro autor, apresentada à Universidade Federal do Ceará (UFC).

2 Mestre em Zootecnia.

${ }^{3}$ Professor - Departamento de Zootecnia - UFC. Correspondência: Av. Mister Hull. S/n Campus do Pici, Cx. Postal 12.168 Fortaleza,

Ceará - CEP: 60.021-970. E.mail: amoura@ufc.br

${ }^{4}$ Professor - Faculdade de Medicina Veterinária - Universidade Estadual do Ceará. E-mail: aaaraujo@zipmail.com
} 
GUNN e GOULD, 1975; COOK et al., 1994). Em adição, a túnica dartos nos ruminantes altera a posição dos testículos em relação ao corpo em função da temperatura ambiente (SETCHELL, 1998) e as glândulas sudoríparas favorecem a evaporação diminuindo a temperatura escrotal (BLAZQUEZ et al., 1988).

$\mathrm{O}$ aumento da temperatura testicular propicia a degeneração seminal (MOORE, 1924; PHILIPS e McKENZIE, 1934; VOGLER et al., 1991), está correlacionada com a redução na fertilidade do macho (GUNN et al., 1942; HULET et al., 1956) e causa alterações na síntese de proteínas e expressão de gens nas células germinativas e células de Sertoli (IKEDA et al., 1999; GUO et al., 1999; KUMAGAI et al., 1999). Variações na temperatura ambiente e umidade relativa do ar também estão associadas a alterações na temperatura corporal de carneiros e, consequentemente, na temperatura testicular (FOOTE et al., 1957; WILDEUS e ENTWISTLE, 1983).

O clima da região Nordeste do Brasil é caracterizado por elevadas temperaturas durante todo o ano, as quais podem influenciar diretamente os mecanismos de termoregulação testicular e, consequentemente, as funções reprodutivas do macho. Entre as raças ovinas exploradas no Nordeste, a Santa Inês é a de maior expressão devido ao porte e produção de leite das matrizes e os reprodutores Santa Inês serem muito utilizados nos esquemas de cruzamentos com animais nativos e de raças exóticas, além desta raça ser bem adaptada à região (OLIVEIRA e LIMA, 1994; NUNES et al., 1997). Os animais Santa Inês são deslanados e esta característica propicia maior tolerância ao calor. A grande maioria dos sistemas de produção do Nordeste utiliza os reprodutores em programas de monta natural, quase sempre a pasto, mas há poucas informações sobre o comportamento de reprodutores ovinos deslanados sob condições de estresse térmico. Portanto, o presente estudo foi conduzido com o objetivo de avaliar o efeito do aumento da temperatura das gônadas, estimulado por intermédio da insulação escrotal, sobre os parâmetros morfo-fisiológicos seminais e a biometria testicular de carneiros Santa Inês no estado do Ceará.

\section{Material e Métodos}

\section{Pré-experimento}

Quatro carneiros da raça Santa Inês, a uma idade de 10 meses, foram submetidos a uma avaliação inicial para se determinar a eficácia de um tipo de insulação escrotal previamente dimensionado. Os testículos foram insulados com bolsas confeccionadas com dupla camada de plástico intercalada de uma camada de algodão e os animais, mantidos em instalações cobertas. As bolsas permaneceram nos animais por sete dias e diariamente foram determinadas a temperatura retal e a temperatura entre a bolsa e a pele do escroto, as quais apresentaram valores médios de $39 \pm 0,18^{\circ} \mathrm{C}$ e $36,9 \pm 0,19^{\circ} \mathrm{C}$, respectivamente.

\section{Tratamentos e coleta de dados}

No experimento utilizaram-se oito carneiros Santa Inês (PC) com idade de 12 meses e peso vivo médio de $53 \pm 1,7 \mathrm{~kg}$. Os animais foram previamente vermifugados e receberam uma dieta à base de feno de leucena, capim-elefante e concentrado (milho, farelo de trigo e soja). O experimento foi realizado nas instalações do Departamento de Zootecnia (Fortaleza - Ceará), situado a $3^{\circ} 45^{\prime} 02^{\prime}$ ' da Latitude Sul e $38^{\circ} 32^{\prime} 35^{\prime}$ ' de Longitude, a oeste de Greenwich, com altitude média de 15,5 m acima do nível do mar. O clima segundo a classificação de Koeppen é do tipo AW. O experimento foi conduzido durante os meses de dezembro a março, apresentando neste período temperatura média de $28,2 \pm 2,3^{\circ} \mathrm{C}$ e umidade relativa do ar de $82,0 \pm 5,0 \%$.

Os oito animais foram submetidos ao processo de insulação escrotal durante sete dias, utilizando a bolsa testada durante o pré-experimento. Os animais permaneceram à sombra, em baia coletiva com uma área de $50 \mathrm{~m}^{2}$. Antes do período de insulação escrotal, realizaram-se duas coletas de dados com intervalo de cinco dias, com a finalidade de determinar a normalidade das características morfo-fisiológicas do sêmen. Durante o período de insulação, foram coletados apenas dados referentes à temperatura retal e à temperatura entre a bolsa e a pele escrotal. A partir do dia em que foi retirada a bolsa de insulação (Dia 0), foram realizadas 11 avaliações dos animais a intervalos de sete a 15 dias, durante um período total de 118 dias. Durante todo o período de insulação escrotal até a conclusão das coletas de dados, os animais foram observados duas vezes ao dia para verificação de possíveis ocorrências de enfermidades ou situações de desconforto, devido ao uso da bolsa de insulação escrotal.

\section{Avaliação seminal}

Amostras de sêmen obtidas por intermédio de eletroejaculação (Torget-65) foram avaliadas quanto a volume do ejaculado, vigor e motilidade individual 
progressiva (CHEMINEAU et al., 1991). Determinou-se a concentração espermática através da diluição de $50 \mathrm{~mL}$ de sêmen puro em $5 \mathrm{ml}$ de solução salina com formol a $0.1 \%$ e posterior leitura em espectofotômetro (CAMPOS, 1999; FREITAS e NUNES, 1992). O pH do sêmen fresco foi determinado através de imersão em fita reagente (Merck). O exame morfológico dos espermatozóides foi realizado através de esfregaço de sêmen fresco corado por meio do Giemsa (TIZOL et al, 1991). Contaram-se 200 células/animal/coleta e as anormalidades espermáticas foram classificadas em maiores e menores (FONSECA et al., 1992).

Análise estatística

Os efeitos da insulação escrotal sobre as medidas testiculares e parâmetros seminais foram avaliados através de análise de variância e Teste de Ducan (Statistical Analysis System, 1997).

\section{Resultados e Discussão}

Durante os sete dias em que os testículos foram insulados, os valores médios de temperatura retal e a temperatura entre a bolsa e a pele do escroto foram $39,3 \pm 0,21^{\circ} \mathrm{C}$ e $37,2 \pm 0,17^{\circ} \mathrm{C}$, respectivamente. Antes da insulação, a temperatura retal média foi de $39,2 \pm 0,3^{\circ} \mathrm{C}$, confirmando que o estresse térmico imposto às gônadas não teve efeito sobre a temperatura retal. Não foram detectadas ocorrências de enfermidades nem de alterações no comportamento dos animais devido à utilização da bolsa escrotal.

$\mathrm{O}$ volume dos ejaculados variou entre $0,4 \pm 0,1 \mathrm{e}$ $1,1 \pm 0,2 \mathrm{~mL}$ (Tabela 1) no decorrer do experimento, porém não houve diferença significativa $(\mathrm{P}>0,05)$ entre as médias das coletas. Os animais apresentaram dificuldade em ejacular entre o $21^{\circ}$ e $50^{\circ}$ dia após a remoção da bolsa de insulação e, coincidentemente, nos períodos em que os aspectos quanti-qualitativos do sêmen ainda não haviam regredido completamente ou quando os mesmos começaram a retornar à normalidade, houve tendência para que o processo de ejaculação ocorresse com maior facilidade. No entanto, a razão destes resultados não pode ser determinada.

Em relação aos padrões do sêmen dos animais avaliados antes do estresse térmico, houve elevação significativa no $\mathrm{pH}$ seminal oito dias após o término da insulação, mas os valores retornaram à normalidade 15 dias após o fim do período de insulação (Tabela 1).

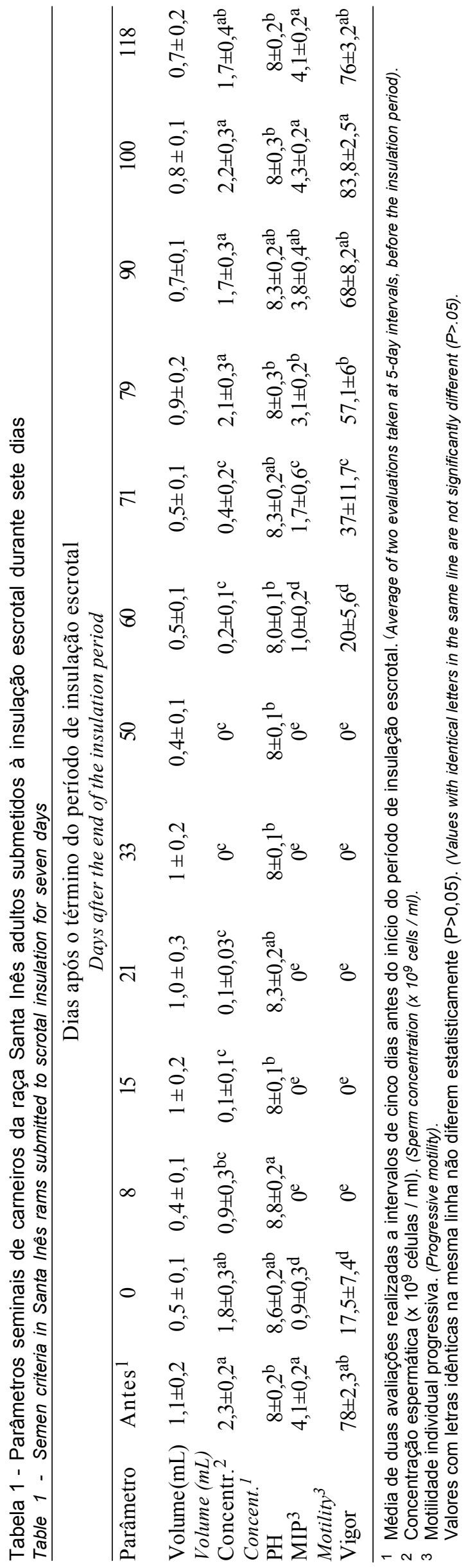


Talvez a alteração nos valores de $\mathrm{pH}$ seja resultante de uma mudança na composição bioquímica dos ejaculados, tanto nas secreções testiculares como epididimárias; além do fato de que a morte dos espermatozóides leva a alterações nos valores de $\mathrm{pH}$. Resultados semelhantes, referentes a volume e $\mathrm{pH}$ dos ejaculados, também foram evidenciados por MUCCIOLO et al. (1974), quando submeteram carneiros da raça Creola à insulação escrotal.

A média dos valores referentes à concentração espermática antes do processo de insulação foi de $2,3 \pm 0,2 \times 10^{9}$ células $/ \mathrm{mL}$ de ejaculado. Ocorreu redução significativa no valor da concentração oito dias após a retirada da bolsa de insulação e os animais apresentaram um quadro de azoospermia entre $33 \mathrm{e}$ 50 dias após o término da fase de insulação (Tabela 1). Depois de 60 dias, foram detectados os primeiros espermatozóides móveis nos ejaculados de alguns animais, mas somente 79 dias após o final do estresse térmico a concentração espermática voltou a apresentar valores semelhantes àqueles observados antes da insulação.

Os animais apresentaram circunferência escrotal (CE) de 26,4 $\pm 1,1 \mathrm{~cm}$ antes da insulação (Figura 1) e as alterações significativas nos valores de CE ocorreram a partir de oito dias após o término do tratamento $(22,4 \pm 0,57 \mathrm{~cm} ; \mathrm{P}<0,05)$. Este valor foi reduzido para $21 \pm 0,3 \mathrm{~cm}$ aos 21 dias após insulação, mas elevouse para $24,9 \pm 0,9 \mathrm{~cm}$ aos 50 dias após o término do período de insulação, ou seja, 29 dias a menos do que o tempo necessário para os parâmetros de concentração espermática retornarem aos valores obtidos antes da insulação. As variações no comprimento testicular durante o experimento foram semelhantes às observadas para a circunferência escrotal (Figura 1), evidenciando que ambas as medidas são indicadores viáveis dos efeitos do estresse térmico sobre as gônadas.

O tempo necessário para formação dos espermatozóides a partir de espermatogônias é de 42 a 53 dias na espécie ovina (COUROT et al, 1970) e o período de permanência destes espermatozóides no epidídimo é de 13 a 15 dias (SWIERSTRA, 1968). No presente estudo, o longo período necessário para o aparecimento de padrões considerados normais de concentração espermática (79 dias) indica que o estresse térmico interferiu com os primeiros estágios da espermatogênese, provavelmente as fases de multiplicação das espermatogônias e início da meiose. Em concordância com esta hipótese, tem sido mostra-

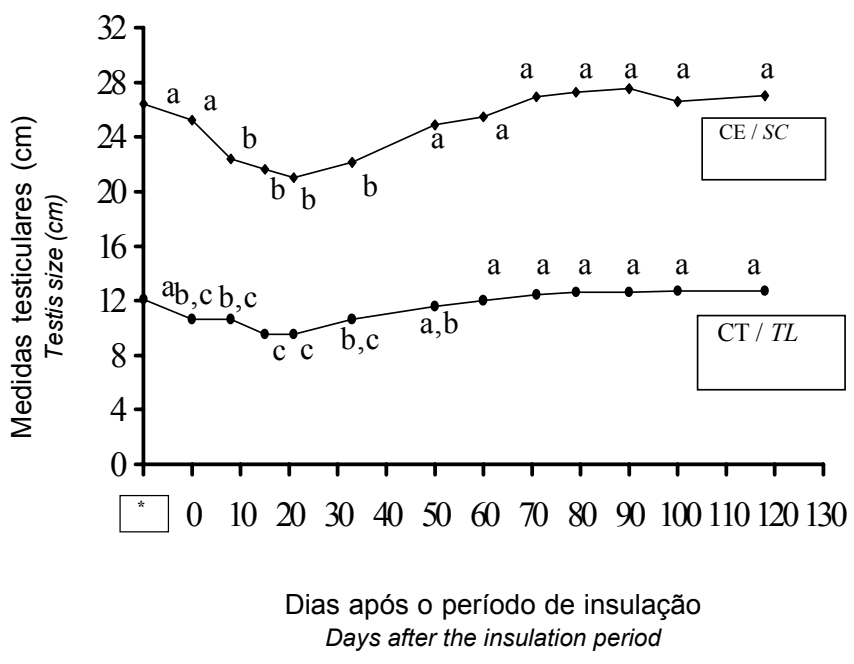

Figura 1 - Circunferência escrotal (CE) e comprimento testicular (CT) em carneiros Santa Inês submetidos à insulação escrotal durante sete dias

Figure 1 - Scrotal circumference (SC) and testicular lenght (TL) in Santa Inês rams submitted to scrotal insulation for seven days

* Média das medidas testiculares avaliadas antes do período de insulação escrotal

* Average testis measurements taken before the insulation period. Valores com letras iguais não diferem estatisticamente $(P>0,05)$.

Values with the same letters are not significantly different $(P>05)$.

do que a exposição de testículos de ratos e camundongos a temperaturas elevadas causa apoptose em espermátides e espermatócitos (LUE et al., 1999; YIN et al., 1999).

Neste estudo, os espermatozóides liberados no ejaculado nos primeiros oito dias após a insulação são aqueles que já haviam sido formados nos túbulos seminíferos e armazenados no epidídimo, principalmente antes da insulação. Devido ao aumento da temperatura escrotal, pode ter havido também alguma reabsorção de espermatozóides anormais no epidídimo, causando assim uma pequena redução na concentração de células no ejaculado, conforme foi observado na primeira coleta após a retirada da bolsa de insulação (Tabela 1). Estudos têm mostrado que, em touros, há reabsorção de espermatozóides com defeitos morfológicos no epidídimo e ductos eferentes (RAO et al., 1980; CRABO et al., 1971).

Alterações na circunferência escrotal também evidenciam que o estresse térmico causou diminuição na população de células germinativas nos túbulos seminíferos. Medidas testiculares estão associadas 
com a produção espermática diária em carneiros (OSINOWO et al., 1992; SOUZA e COSTA, 1992), número de espermátides por célula Sertoli e área dos túbulos seminíferos, além de apresentarem relação inversa com a taxa de degeneração de células germinativas em touros (BERNDTSON et al., 1987; MOURA e ERICKSON, 1997; PALASZ et al., 1994). Embora a variável consistência testicular não tenha sido submetida à análise estatística, foi observado que os testículos apresentaram-se flácidos já a partir do dia em que foi removida a bolsa de insulação, o que evidencia um processo de degeneração das células germinativas nos túbulos seminíferos. O retorno à consistência normal das gônadas coincidiu com a elevação gradual da concentração espermática. A diminuição na consistência do parênquima testicular está associada a uma redução na produção de espermatozóides (COULTER e FOOTE, 1979) e maior número de espermatócitos e espermátides degeneradas em todos os estágios do ciclo da espermatogênese em touros (MULLER et al., 1992).

Alterações na motilidade progressiva individual e vigor dos espermatozóides surgiram mais rapidamente do que aquelas observadas na concentração espermática e medidas testiculares. Logo na primeira coleta após a insulação, houve decréscimo acentuado na motilidade, o que evidencia a existência de efeito direto da temperatura, e mais rápido, sobre o epidídimo. O retorno da motilidade espermática aos padrões observados antes da insulação ocorreu 90 dias após o término do estresse térmico (Tabela 1). Também é importante o fato de que, como a produção de células germinativas deve ter sido reduzida nos túbulos seminíferos, seriam necessários pelo menos 58 a 67 dias para o aparecimento de novos espermatozóides no epidídimo, 43 a 52 dias para o processo de espermatogênese e 15 dias para o processo de transporte e diferenciação das células no epidídimo. No entanto, dado que o retorno dos valores de motilidade espermática ao normal requereram mais que 67 dias, é provável que a temperatura elevada causou danos à funcionalidade do epidídimo, os quais também levaram mais tempo para serem reparados. CÓSER et al. (1979), trabalhando com carneiros deslanados no Brasil, encontraram alterações semelhantes, excetuando apenas o retorno à normalidade que ocorreu mais precocemente, ou seja, em torno de 60 dias. Em caprinos nativos submetidos à insulação escrotal durante 6,5 dias, na região Nordeste do Brasil, foram necessários 63 dias para que os valores de motilidade espermática retornassem ao normal (SANTOS e SIMPLÍCIO, 1993; SANTOS et al., 1998). Em que pese as diferenças na temperatura ambiente e nos procedimentos experimentais utilizados, os resultados destes estudos indicam que pode haver diferenças significativas entre espécies e raças com relação aos efeitos do estresse térmico sobre a fisiologia das gônadas.

As avaliações realizadas antes da insulação demonstraram que os ejaculados dos carneiros apresentaram 88,4 $\pm 0,9 \%$ de espermatozóides com características morfológicas normais e 11,6\% com defeitos totais (Tabela 2), sendo estes últimos distribuídos entre defeitos maiores $(1,7 \pm 0,3 \%)$ e menores $(9,9 \pm 0,9 \%)$. Do total de células com defeitos maiores, 1,04\% apresentaram-se com gota citoplasmática proximal. Ainda na fase que antecedeu a insulação, dos $9,9 \%$ de células espermáticas com defeitos menores, observou-se com maior frequência células com cabeça normal livre (2\%), gota citoplasmática distal $(1,8 \%)$, cauda dobrada $(2,4 \%)$ e cauda enrolada na extremidade $(3,3 \%)$. Na primeira colheita após a insulação, a proporção de defeitos totais aumentou significativamente para $47 \pm 8,0 \%$, mais devido ao aumento da proporção de defeitos menores $(43,4 \pm$ $5,4 \%)$ do que de defeitos maiores $(3,6 \pm 2,6 \%)$. Nesta fase, as células com defeitos menores caracterizaram-se por apresentar cabeça normal livre $(11,1 \%)$, gota distal $(1,9 \%)$, cauda enrolada $(14,5 \%)$ e cauda enrolada na extremidade $(15,9 \%)$. Com relação aos defeitos maiores, o número de células com cabeça anormal livre representou $2,2 \%$, enquanto o de células com gota proximal manteve-se sem alterações $(1,1 \%)$. Células com cabeça anormal livre não haviam sido detectadas antes da insulação. A proporção de defeitos maiores permaneceu significativamente diferente $(\mathrm{P}<0,05)$ entre oito e 21 dias após o tratamento e, nestes períodos, houve maior ocorrência de células espermáticas subdesenvolvidas, com cabeça pequena anormal, cabeça anormal livre e com gota proximal. Aos 60 dias após o período de insulação, observou-se células subdesenvolvidas $(5,06 \%)$, células com cabeça pequena anormal $(4,6 \%)$ e com gota proximal $(4,1 \%)$ como os tipos de defeitos maiores mais frequentes. Entre 71 e 118 dias após a insulação, a proporção de células espermáticas subdesenvolvidas reduziu de 2 para $0,05 \%$ e as com gota proximal, de 3,05 para $0,6 \%$, respectivamente. Células com cabeça pequena anormal ainda foram detectadas entre os dias 71 e 90, mas em proporções semelhantes 
(entre 0,17 e $0,05 \%$ ) às determinadas antes da fase de insulação. Entre 33 e 50 dias, os animais não liberaram espermatozóides, razão pela qual não são apresentados dados de morfologia espermática neste período. No final do experimento, ou seja, 118 dias após o término do tratamento, a percentagem de defeitos totais era de $25,1 \pm 1,5 \%$, não devido aos defeitos maiores $(0,7 \pm 0,1 \%)$, mas em função dos defeitos menores, os quais mantiveram-se na proporção de $24,4 \pm 1,4 \%$.

Nos períodos de avaliação após a insulação escrotal, a maior parte dos defeitos menores observados foi do tipo cabeça normal livre, gota distal, cauda dobrada e cauda enrolada na extremidade. Entre os dias 8 e 21 após a insulação, observaram-se com mais frequência células com cabeça normal livre (31,2 a $34,9 \%)$ e células com cauda dobrada (20,7 a 1,8\%), enquanto que apresentaram menor proporção espermatozóides com gota citoplasmática distal $(2,13$ a $1,5 \%)$ e com cauda enrolada na extremidade (5,2 a $1,8 \%)$. Entre 71 e 118 dias, houve decréscimo do número de células com cabaça normal livre $(13,7$ para $6,7 \%)$, células com cauda dobrada $(14,9$ para $7,5 \%)$ e de células com cauda enrolada na extremidade $(8,3$ para $5,1 \%)$. No entanto, a proporção de espermatozóides com gota distal neste período apresentou pouca variação $(4,7 \%$ aos 71 dias e $4,8 \%$ aos 118 dias). CÓSER et al. (1979) também observaram aumentos significativos na percentagem de espermatozóides com defeitos após a insulação escrotal em carneiros, mas o retorno à normalidade ocorreu mais rápido do que o verificado no presente estudo. Dos defeitos maiores foram encontrados com maior frequência gota citoplasmática proximal, cabeça pequena anormal e células decapitadas, enquanto cabeça normal livre, cauda dobrada e enrolada representaram as anormalidades de maior incidência como defeitos menores. WILDEUS e ENTWISTLE (1983) também observaram, em testículos de touros insulados durante 48 horas, aumento significativo no número de espermatozóides com defeitos de cabeça 14 dias após o término da insulação escrotal. A ocorrência destes defeitos oito dias após a término do período de insulação sugere que os efeitos do estresse térmico ocorreram sobre a morfologia dos espermatozóides presentes no epidídimo. Dado o período de trânsito dos espermatozóides ser de aproximadamente 15 dias no epidídimo em carneiros (COUROT et al., 1970), a existência de espermatozóides com defeitos maiores

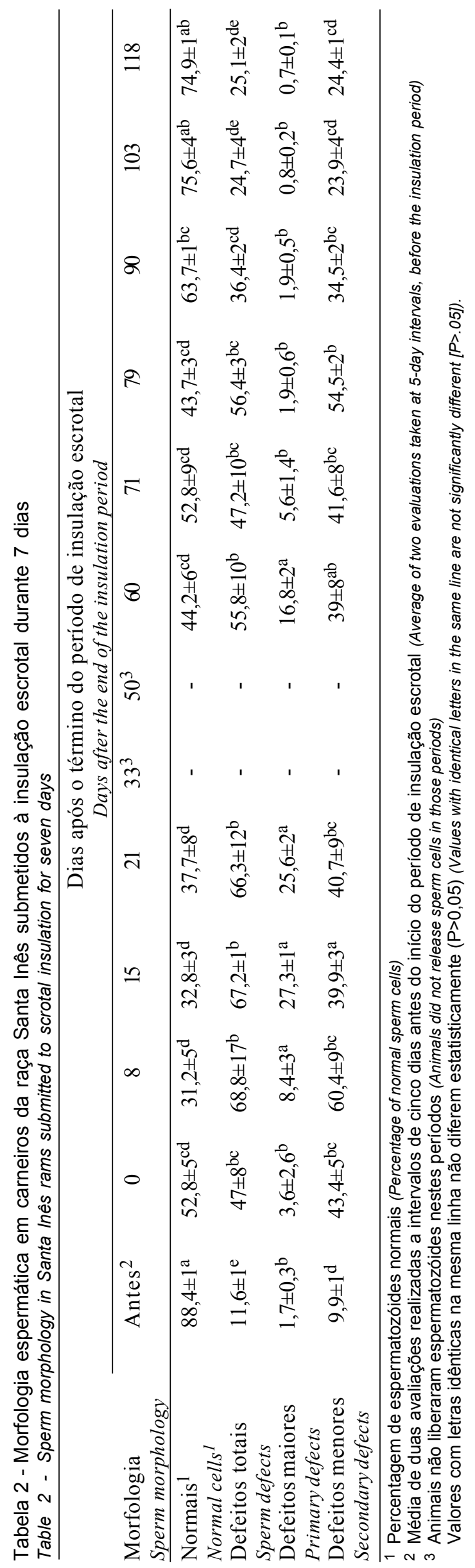


colhidos entre 15 e 21 dias após a insulação evidencia também os efeitos do estresse térmico sobre os estágios finais da espermiogênese. Com os dados disponíveis não se pode definir a razão pela qual a proporção de defeitos menores permaneceu elevada por um período de tempo tão longo, mas este fato mostra claramente a grande susceptibilidade do epidídimo de carneiros ao estresse térmico.

\section{Conclusões}

O estresse térmico causou efeitos deletérios tanto na espermatogênese como no processo de maturação dos espermatozóides, no epidídimo, dados a rapidez com que as alterações na produção espermática foram detectadas e o tempo necessário para o retorno à normalidade. O estudo também mostra que estes efeitos são reversíveis, evidenciando a resistência do epitélio seminífero a efeitos de fatores ambientais.

As medidas testiculares constituem-se em critérios adequados para avaliação do efeito do estresse térmico sobre a produção espermática. Deve ser considerado, no entanto, que a motilidade espermática e a porcentagem de defeitos menores apresentam maior sensibilidade ao estresse térmico e alterações nestes parâmetros podem surgir antes mesmo de serem detectadas alterações significativas na biometria testicular.

\section{Referências Bibliográficas}

BERNDTSON, W.E., IGBOELI, G., PARKER, W.G. 1987. The numbers of Sertoli cells in mature Holstein bulls and their relationship to quantitative aspects of spermatogenesis. Biol. Reprod., 37:60-74.

BLASQUEZ, N.B., MALLARD, G.F., WEDD, S.R. 1988. Sweat glands of the scrotum of the bull. J. Reprod. Fert ., 83:673-677.

CAMPOS, A.C.N. 1999. Água de côco criopreservada proveniente de frutos de diferentes variedades e idades de maturação como diluidor do sêmen caprino. Fortaleza, CE: UECE, 1999. 45p. Dissertação (Mestrado em Ciências Veterinárias). Faculdade de Veterinária, Universidade Estadual do Ceará, 1999.

CHEMINEAU, P., COGNIÉ, Y., GUÉRIN, Y. et al. 1991. Training manual on artificial insemination in sheep and goats. Rome: FAO, 222p.

COOK, R.B., COUlTER, G.H., KASTELIC, J.P. 1994. The testicular vascular cone, scrotal thermoregulation, and their relationship to sperm production and seminal quality in beef bulls. Theriogenology, 41:653-671.

CÓSER, A.M.L., GODINHO, H.P., FONSECA, V.O. 1979. Efeito de altas temperaturas sobre a espermatogênese de carneiros brancos deslanados em condições experimentais. Arq. Esc. Vet. UFMG, 31(2):147-154.

COUlter, G.H., FOOTE, R.H. 1979. Bovine testicular measurements as indicators of reproductive performance and their relationship to productive traits in cattle: a review. Theriogenology., 11:297-310.

COULTER, G.H., KASTELIC, J.P. Testicular thermoregulationin bulls. In: TECHNICAL CONFERENCE ON ARTIFICIAL INSEMINATION AND REPRODUCTION, 15, 1994, Columbia. Proceedings... Columbia: National Association of Animal Breeders. 1994. p.28-34.

COUROT, M., HOCHEREAU de-REVIERS, M.T., ORTAVANT, R. 1970. Spermatogenesis. In: JOHSON, A.D., GOMES, W.R., VANDEMARK, N.L. (Eds.) The testis. New York: Academic Press. p.339.

CRABO, B., GUSTAFSSON, B., NICANDER, L. et al. 1971. Subnormal testicular function in a bull concealed by phagocytosis of abnormal spermatozoa in the efferent ductules. J. Reprod. Fert., 26:393-396.

FONSECA, V.O., VALE FILHO, V.R., MIES FILHO, A. et al. 1992. Procedimentos para exame andrológico e avaliação de sêmen animal. Belo Horizonte: Colégio Brasileiro de Reprodução Animal. 79p.

FOOTE, W.C., POPE, A.L., NICHOLS, R.E. et al. 1957. The effects of variations in ambiente temperature and humidity on rectal and testis temperarure of sheared and unsheared rams. J. Anim. Sci., 16:144-150.

FREITAS, V.J.F., NUNES, J.F. 1992. Parâmetros andrológicos e seminais de carneiros deslanados criados na região litorânea do Nordeste Brasileiro em estação seca e chuvosa. R. Bras. Reprod. Anim., 16: 95-104.

GERONA, G.R., SIKES, J.O. 1970. Effects of elevated scrotum temperature on spermatogennesis and semen characteristics. J. Dairy Sci., 53:659-670.

GUNN, S.A., GOULD, T.C. 1975. Vasculature of the testes na adnexa. In: GREEP, R.O., ASTWOOD, E.B. (Eds.) Handbook of Physiology, Section 7 Endocrinology. Washington D.C.: American Physiology Society. v.5, p.117-142.

GUNN, R.M.C., SANDERS, R.N., GRANGER, W. 1942. Studies of fertility in sheep. 2. Seminal changes affecting fertility in rams. Coun. Sci. Industr. Res. Australia, Bul. No 148.

GUO, C. X., TANG, T.S., MU, X.M. et al. 1999. Cloning of novel temperature-related expressed sequence tags in rat testis during spermatogenesis. Biochem. Biophys. Res. Com. 258:401-406.

HULET, C.V., VOIGTLANDER H.P., POPE, A.L. et al. 1956. The nature of early season infertility in sheep. J. Anim. Sci., 15:607-615.

IKEDA, M., KODAMA, H., FUKUDA, J. et al. 1999. Role of radical oxygen species in rat testicular germ cells apoptosis induced by heat stress. Biol. Reprod., 61:393-399.

KASTELIC, J.P., COOK, R.B., COULTER, G.H. et al. 1995. Insulating the scrotal neck affects semen quality and scrotal/ testicular temperatures in the bull. Theriogenology, 45:935-941.

KUMAGAI, J., FUKUDA, J., KODAMA, H. et al. 2000. Germ cell-specific shock protein 105 binds to p53 in a temperaturesensitive manner in rat testis. Eur. J. Biochem., 267:3073-3078.

MOORE, C.R. 1924. Heat application and degeneration testicular; the function of the scrotum. Am. J. Anat. 34:337-349.

MOURA, A., ERICKSON, B.H. 1997. Age-related changes in peripheral hormone concentrations and their relationships with testis size and number of Sertoli and germ cells in beef bulls. J. Reprod. Fert. 111:183-190.

MUCCIOLO, R.G., BARNABE, R.C., BARNABE, V.H. 1974. Variações no quadro espermático de carneiros submetidos à degeneração testicular experimental. R. Fac. Med. Vet. Zootec. 
USP, 11:155-177.

MULLER, E., RODRIGUEZ MARTINEZ, H., BRADEN, S. et al. 1992. Testicular ultrastructure of Zebu bulls in Costa Rica. J. Vet. Med., 39:382-391.

NUNES, J.F., CIRÍACO, A.L.T., SUASSUNA, U. 1997. Produção e reprodução de ovinos e caprinos. 2.ed. Fortaleza, Ceará. p.23-53.

OLIVEIRA, A.A.P., LIMA, V.P.M.S. Aspectos econômicos da caprino-ovinocultura tropical brasileira. In: SEMANA DA CAPRINOCULTURA E DA OVINOCULTURA TROPICAL BRASILEIRA, 1994, Sobral. Anais... Sobral: EMBRAPA-CNPC, 1994.

OSINOWO, O.A, MARRIE, B.N. EKPE, G.A. 1992. Preliminary study of postnatal growth and reproductive tract development in Yankasa rams. Anim. Reprod. Sci., 27:49-54.

PALASZ, A.T., CATES, W.F., BARTH, A.D. et al. 1994. The relationship between scrotal circumference and quantitative testicular traits in yearling beef bulls. Theriogenology, 42:715-729.

PHILIPS, R. W., McKENZIE, F.F. 1934. The thermo-regulatory function and mechanism of the scrotum. Mo. Agr. Exp. Sta. Res. Bul., 217-219.

RAO, A.R., BANE, A., GUSTAFSSON, B. 1980. Changes in the morphology of spermatozoa during their passage through the genital tract in dairy bulls with normal and impaired spermatogenesis. Theriogenology, 14:1-12.

SANTOS, D.O., SIMPLÍCIO, A.A. 1993. A insulação escrotal na fertilidade de caprinos adultos. Ciência Animal, 3:14-25.

SANTOS, D.O., SIMPLÍCIO, A.A., MACHADO, R. 1998. Características escroto-testiculares e do ejaculado em bodes mestiços submetidos à insulação escrotal. Arq. Bras. Med. Vet. Zootec., 50: 287-291.

SAS. Institute Inc., SAS/ STAT( User's Guide, Version 6, Fourth Edition, Volume 2, Cary, NC: SAS Institute Inc., 1997. 846p.
SETCHELL, B.P. 1998. The parkers lecture - heat and the testis. J. Reprod. Fertil., 114:179-194.

SOUZA, J.A.T., COSTA, F.A.L. Características do sêmen e correlação com outros parâmetros reprodutivos em ovinos deslanados. In: SIMPÓSIO EM CIÊNCIAS AGRÁRIAS PESQUISA COM CAPRINOS E OVINOS NO CCA, 1992, Teresina, PI. Anais... Teresina, 1992. p.80-86.

SWIERSTRA, E.E. 1968. Cytology and duration of the cycle of the seminiferous epithelium of the boar. Duration of spermatozoan transit through the epididymis. Anat. Rec., 161:171-185.

TIZOL, G., DUQUE, D., CARDENAS, A. 1991. Técnica de eosina-nigrosina para la determinacion de reacciones acrosomáticas en espermatozoides vivos. Revista Cubana de Ciências Veterinárias 22:73-83.

VOGLER, C.J., SAACKE, R.G., BAME, J.H. et al. 1991. Effects of scrotal insulation on viability characteristics of cryopreserved bovine semen. J. Dairy Sci., 74:3827-3835

WAITES, G.M.H. 1970. Temperature regulation and the testis. In: JOHNSON, A.D., GOMES, W.R., VANDERMARK, N.L. (Eds.) The testis. New York: Academic Press. p.241-279.

YIN, Y.Z., HAWKINS, K.L., DEWOLF, W.C. et al. 1997. Heat stress causes testicular germ cell apoptosis in adult mice. J. Androl., 18:159-165.

Recebido em: $27 / 09 / 00$

Aceito em: 29/06/01 